\title{
Development of Noise-free Digital Interfaces: Hand-drawn interfaces for consumer wellbeing
}

\author{
Joskaudè Pakalkaitè \\ Falmouth University, The Academy of \\ Innovation \& Research \\ Penryn Campus, Treliever Road, \\ Penryn, Cornwall TR10 4RH, UK \\ j.pakalkaite@falmouth.ac.uk
}

\section{INTRODUCTION}

My research project focuses on design challenges associated with the negative impact of mainstream consumer electronics such as notifications and colourful home screens. These design challenges led me to reimagine alternative design solutions and develop work that explores the practice of Human-Computer Interaction and design. The emphasis of this report is the exploration of handdrawn interfaces and how this could be applied to the production of devices and tech tools to promote digital wellbeing. In my project, I explore the issue of noisy digital interfaces through three different elements: visual attention, tactility and mindfulness. The focus of this paper is on the element of visual attention.

\section{DESIGN CHALLENGES AND PROPOSALS}

My response to the challenges of Misuse of Colour and Shapes in UI Design and Cold 'Generic' Interfaces is to design a feature phone with a handdrawn interface, and redesign notifications and the home screen for the device. Using the contrast of colourful and greyscale elements will sort incoming signals for the user by urgency. I will go even further and speculate whether that the elimination of colours might potentially reduce app and device overuse. This project, therefore, explores monochrome design.

Furthermore, I propose that hand-drawn digital interfaces constitute a new concern in $\mathrm{UI}$ and Human-Computer Interaction research. This research poses possibilities for hand-drawn digital interfaces to promote digital wellbeing largely by mitigating 'noise' in the digital interface, and potentially providing a more user-friendly and emotional experience for consumers more broadly.

\section{HAND DRAWN INTERFACE: YOSHI PHONE}

Research through Design is a recognised way of designing products and services as it focuses on the design of the artefact and its main elements as a way of generating and communicating new knowledge (Stappers, Giaccardi 2016). The main goal of my study is to develop design solutions (noise-free digital interfaces) to the problem (noisy digital interfaces), which suggests that my project needs to provide prototypes. I therefore chose the Research through Design approach because the focus on designing prototypes aligned with the aims and objectives of my study.

The Research through Design approach is still in its formative stage meaning there are various models and practices within this approach (Stappers, Giaccardi 2016). For that reason, the designer must choose the most appropriate method for the project based on its unique set of design challenges and solutions. The main challenge for designers is to create ethical technologies that are beneficial for consumer wellbeing. This should be addressed by large IT companies. Design fiction is also often applied in generating innovative solutions by tech companies within the industry. This is why the method of Design Fiction was selected, because it allows the designer to propose and test alternative solutions and innovate.

There are also several ways of creating design fiction. After reviewing these, I chose the methodology used in 'The Poetics of Design Fiction' (Markussen, Knutz 2014). The decision behind this choice was that the methodology in their study was adapted and performed from creative specialties such as photography, illustration and design, which are the most relevant to this study. Also, this project is an example of 
how an illustrator can successfully produce a design fiction.

In this project, the development of ideas stems from the design challenges and solutions. The 'What if scenario' was also inspired by the design challenges and proposals. The 'What if scenario' for the Yoshi phone is 'What if a feature phone could have a hand-drawn interface?'. This scenario was then used to sketch and explore the look of the Yoshi Phone (see Figure 1). 'Yoshi Phone' is the first feature phone with a minimalistic hand-drawn user interface, which is gentle on users' attention.

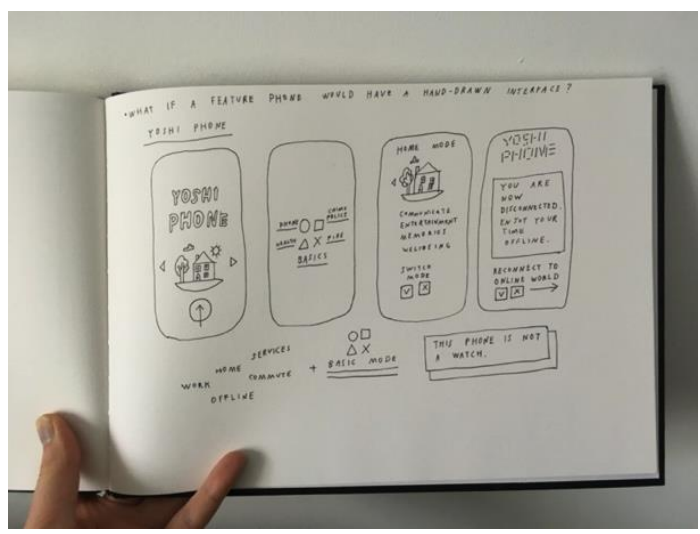

Figure 1: What if scenario for Yoshi Phone.
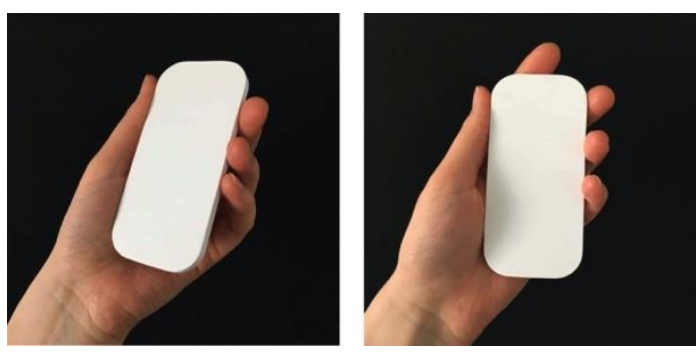

Figure 2: Yoshi Phone 3D Prototype.

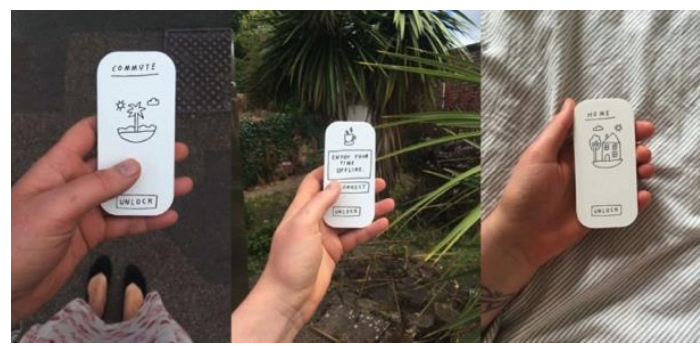

Figure 3: Yoshi Phone.

After the 3D prototype (see Figure 2) was designed and printed, the next stage was to develop the interface design for the feature phone. Instead of apps, the feature phone has modes based on activities/places associated with the tasks. The menu of this phone has different modes: Basics, Home, Work, Commute, Well-being and Offline, which offer the user tasks most likely to be associated with the location. The Yoshi Phone has two views that users can select: Icon View and Non-Icon View. These views communicate lownoise digital interfaces. Non-Icon view provides a less distracting experience. Yoshi Phone also does not show time.

The interface design for the Yoshi Phone has been hand-drawn and scanned in. The drawings were then edited on Adobe Photoshop. The hand-drawn interface has been placed on the 3D prototype to simulate the way this fictional prototype works (see Figure 3). The final prototype will also have stickers to simulate the screen interface.

I am currently at the stage of developing design fiction narratives for the Yoshi Phone. There will be two types of design fiction: a fictional user manual and promotional material such as booklets with illustrated narratives, postcards. The promotional material narratives will be developed by screenwriter George Forster. After the narratives are developed, I will illustrate and design them. The user manual and promotional materials will then be printed in a limited edition. Due to Covid-19 regulations, the design narratives will be photographed and presented online instead of exhibited face to face as initially planned.

\section{FINDINGS}

After the fictional narratives are produced, they will be distributed together with the diegetic prototypes and an online questionnaire to industry professionals such as UI and UX designers, software developers and engineers to gain feedback. The insights collected from the industry professionals will be analysed and presented as part of the results of this study.

I predict that noisy digital experiences can be mitigated by implementing mindful elements, purposefully using colours and shapes, hand-drawn interfaces, and touch-rich interactions, when designing noise-free digital interfaces. This prediction is explored through practice-based research by developing prototypes.

\section{REFERENCES}

Soegaard, M. and Dam, R F. (2016) The Encyclopaedia of Human- Computer Interaction, $2^{\text {nd }}$ Edition. The Interaction Design Foundation.

Markussen, T, Knutz, E. (2014) The Poetics of Design Fiction. DPPI 13: Proceedings of the 6th International Conference on Designing Pleasurable Products and Interfaces, September 2013, 231-240. 